\title{
Effects of UV-B radiation and simulated herbivory on phlorotannins in the brown alga Ascophyllum nodosum
}

\author{
Henrik Pavia*, Gunnar Cervin, Annelie Lindgren, Per Åberg \\ Department of Marine Botany, University of Göteborg, Carl Skottsbergs Gata 22, S-413 19 Göteborg, Sweden
}

\begin{abstract}
Models and experiments seeking to explain intraspecific variation in brown algal phlorotannins (polyphenolics) have mainly focused on the effect of 2 factors, herbivory and resource availability (carbon/nutrients). The possible importance of other biotic and abiotic factors, e.g. pathogenic micro-organisms, heavy metals and UV radiation, has often been suggested but only rarely experimentally tested. In the present study the effects of increased UV-B irradiance and simulated grazing (clipping) on phlorotannin production in the brown alga Ascophyllum nodosum were investigated. The 2 treatments were applied simultaneously in a crossed factorial experiment in order to test for interactive, as well as separate, effects. Carbon and nitrogen content of the algae was also determined for each treatment. The effect of the experimental treatments on the feeding selectivity of a natural herbivore was tested in a subsequent feeding preference experiment with the crustacea Idotea granulosa. An increase ( $50 \%$ ) in UV-B radiation during a $2 \mathrm{wk}$ period resulted in a significant increase $(\sim 30 \%)$ in mean phlorotannin concentration, while no significant changes in phlorotannin levels following simulated grazing were observed. The additional UV light caused a slight increase in the nitrogen content of the algae, indicating that the response in phlorotannin production was not caused by nutrient deficit. Absorption spectra of $A$. nodosum extracts, before and after removal of phlorotannins with polyvinylpolypyrrolidone, revealed that phlorotannins can contribute to absorption in the UV-B range $(280$ to $320 \mathrm{~nm}$ ). The results imply that phlorotannins can function as inducible screens against harmful UV radiation. The grazer I. granulosa showed a clear preference for algae that had been exposed to an addition of UV-B radiation, in spite of their increased phlorotannin levels, supporting the notion that small marine herbivores in general are tolerant to chemical defenses of algae.
\end{abstract}

KEY WORDS: Brown algae - Ascophyllum - Chemical defenses - Herbivory · Idotea - Induced responses - Isopods · Phlorotannins · Polyphenolics - Seaweeds - UV-B radiation

\section{INTRODUCTION}

Phlorotannins (polyphenolics) in marine brown algae are generally assumed to function as chemical defenses against herbivores (Ragan \& Glombitza 1986. Steinberg 1992). Consequently, research on algal phlorotannins has been influenced by general plantherbivore theories, developed mainly within the field of terrestrial ecology. One such example is the induced defense model (e.g. Karban \& Myers 1989, Harvell 1990) based on the assumption that there is a cost in

·E-mail: henrik.pavia@marbot.gu.se production of defenses. According to the induced defense model plants should allocate more resources to defenses when herbivores are present and active. The occurrence of induced chemical defenses is well documented in terrestrial plants (Karban \& Myers 1989, Herms \& Mattson 1992), whereas induced defense models have only been addressed in a few studies on phlorotannins in marine algae, with inconclusive results (see Hay \& Fenical 1992, Peckol et al. 1996). To establish the degree to which induced defense theory is applicable to phlorotannin production in brown algae will require more experimental data from several taxa and geographical areas. 
Herbivory is not the only factor that can influence production of plant phenolics. For instance, a positive relationship between solar radiation and tannin production is well established for terrestrial plants (Waterman \& Mole 1994 and references therein) and the same relationship has been reported for phlorotannins in algae (Yates \& Peckol 1993). The most common explanation for this at the intraspecific level is the carbon/nutrient (C/N) balance model (Bryant et al. 1983). According to the $\mathrm{C} / \mathrm{N}$ balance model the production of polyphenolics, and other $\mathrm{C}$-based secondary metabolites, is governed by the relative supply of carbon (through photosynthesis) and essential nutrients. Consequently, polyphenolic production should increase under conditions of high irradiance and low nutrient availability. An alternative, less often advocated explanation for the effect of solar radiation on polyphenolic production is that polyphenolics are produced as protection against photodestruction caused by UV light. In terrestrial plants there is evidence that increased phenolic production can be induced by UV light and that these phenolics can absorb UV radiation and thereby protect the plant cells (D'Surney et al. 1993, Waterman \& Mole 1994). The possible effect of UV radiation on phlorotannin production in brown algae has not previously been examined.

The multiple function of plant phenolics implies that phlorotannin production in algae is likely to be determined by an interaction of several biotic and abiotic factors. Such interactive effects could explain the large intraspecific variation in phlorotannin found on different, including very small, spatial scales (Pavia \& Åberg 1996) as well as seasonal variations (Ragan \& Glombitza 1986). Testing for synergistic or antagonistic effects among different factors requires that different experimental treatments are applied together in experiments with factorial combinations of treatments. Here we present an experiment where we tested the hypotheses that 2 different treatments, simulated grazing and increased UV-B radiation, can, separately or interactively, induce changes in phlorotannin concentration in the brown seaweed Ascophyllum nodosum (L.) Le Jol. For induced defense models to be relevant for brown algal phlorotannins any induced changes in the production of phlorotannins should affect natural grazing patterns. Accordingly, we also assessed how the treatments in the induction experiment affected the susceptibility of $A$. nodosum plants to the crustacean grazer Idotea granulosa Rathke.

\section{MATERIAL AND METHODS}

Study sites and organisms. Ascophyllum nodosum grows on rocky shores in the intertidal zone on the coasts of the Northern Atlantic. The present study was done in the Tjärnö area on the Swedish west coast $\left(58^{\circ} 54^{\prime} \mathrm{N}, 11^{\circ} 07^{\prime} \mathrm{E}\right)$. Because of the small tidal range $(\leq 0.3 \mathrm{~m})$ at Tjärno the vertical distribution of $A$. nodosum is limited and the width of the A. nodosum zone is maximum 3 to $4 \mathrm{~m}$ and usually less than $1 \mathrm{~m}$ ( $\AA$ berg 1990). However, the abundance and population structure of $A$. nodosum within this narrow zone is similar to what has been observed in the midintertidal zone on coasts with larger tidal amplitudes (Åberg \& Pavia 1997). In the Tjärnö area, A. nodosum plants are inhabited by several potential grazers, so-called mesoherbivores (Brawley \& Fei 1987), e.g. the gastropod Littorina obtusata (L.), the amphipod Gammarus locusta (L.) and the isopod Idotea granulosa (Pavia unpubl.). For the feeding preference experiment we used adult individuals of I. granulosa, which are important grazers of fucoids in temperate waters (e.g. Salemaa 1987), including $A$. nodosum ( $\mathrm{H}$. Pavia, H. Carr \& P. Åberg unpubl.).

In March 1995 Ascophyllum nodosum plants were collected haphazardly from several sites in the Tjärnö archipelago. Individuals larger than about $100 \mathrm{~g}$ wet mass were exclucled from sampling. The algae were transplanted to the experimental site in a small bay outside the Tjärnö Marine Biological Laboratory. Alongside a bridge in the bay an experimental frame had been constructed where algae could be fixed at the natural depth of A. nodosum at the Swedish west coast. The surrounding substrate was sediment with just a few fucoid plants on occasional boulders. This means that the risk of interfering herbivore damage to the experimental plants by natural grazers was small during the course of the experiment. Before starting the induction experiment all plants were cleared of visible grazers

Induction experiment. The induction experiment was run for 2 wk in April 1995. Damage by herbivores was simulated in a way similar to previous experiments on induction of phlorotannins in brown algae (Van Alstyne 1988, Yates \& Peckol 1993, Steinberg 1994, Peckol et al. 1996). At the start of the induction experiment 24 of the 48 plants were randomly chosen and clipped with a hole punch in order to mimic size and shape of naturally occurring damage. Clipping damage was evenly distributed all over the vegetative tissue of each plant until 10\% of the wet weight was removed.

In the air above the algae we put 2 aluminium frames with Q-panel UV-B-313 fluorescent tubes and 2 control frames without fluorescent tubes. To obtain a balanced number of replicates for each factorial combination 12 Ascophyllum nodosum individuals, 6 clipped and 6 undamaged individuals, were placed in random order underneath each frame. In order to filter out 
wavelengths $<295 \mathrm{~nm}$ the fluorescent tubes were covered with preburned ( $6 \mathrm{~h}$ with UV-B fluorescent tubes) cellulose diacetate film (Erik S. Ekman AB, Stockholm) that was exchanged every $48 \mathrm{~h}$. The UV-B fluorescent tubes were turned on for $6 \mathrm{~h} \mathrm{~d}^{-1}$ (09:00 to 15:00 h). The natural daylength during the induction experiment was about $14 \mathrm{~h}$. The distance from the frames to the algae was $\sim 1 \mathrm{~m}$ and during low water, when the experimental plants were above water level, the UV frames increased the UV-B irradiance by approximately $0.6 \mathrm{~W}$ $\mathrm{m}^{-2}$ ( $-50 \%$ above ambient). The weather was mostly clear and sunny during the experiment and photosynthetically active radiation (PAR) during the hours of UV-B treatment was on an average $\sim 1400 \mu \mathrm{E} \mathrm{m}^{-2} \mathrm{~s}^{-1}$ and $U V-A$ radiation $\sim 35 \mathrm{~W} \mathrm{~m}^{-2}$. The addition of PAR and UV-A from the fluorescent tubes was negligible. Light measurements were made with an International Light $1400 \mathrm{~A}$ photometer equipped with cosine-corrected sensors (detector types SUL 033 and SUL 240) and the readings were corrected for spectral sensitivity of the sensors and the solar and UV-B fluorescent tube spectra. Correction factors were determined through simultaneous measurements with the IL1400A photometer and an IL1700 radiometer.

Algal tissue constituents. At the start and end of the experiment 2 apical shoots, of about $0.25 \mathrm{~g}$ each, were cut from each of the 48 plants. One shoot was used for phlorotannin analysis and one for individual dry to wet weight ratio determination. Samples for dry weight determination were dried for $48 \mathrm{~h}$ at $60^{\circ} \mathrm{C}$ while phlorotannin samples were rapidly frozen in liquid nitrogen and stored at $-80^{\circ} \mathrm{C}$. In the laboratory the phlorotannin samples were ground with liquid nitrogen in a mortar and put in aqueous methanol that was flushed with nitrogen gas to remove oxygen. Phlorotannins were extracted in the dark at $4^{\circ} \mathrm{C}$ for $24 \mathrm{~h}$ and quantified by the Folin-Denis method (Ragan \& Jensen 1977, Steinberg 1985, 1989, Ragan \& Glombitza 1986). Phloroglucinol (1,3,5-trihydroxybenzene, Merck art. 7069) was used as a standard

Dry weight samples collected at the end of the induction experiment were later used for determination of carbon and nitrogen contents in algal tissues. The samples were ground and analyzed in an elemental analyzer (FISONS Instruments NA 1500 NC).

UV spectra. In order to examine the possible contribution of phlorotannins to absorption of UV-B radiation, absorption spectra of the pooled extract from several Ascophyllum nodosum plants were measured both before and after removal of phlorotannins with polyvinylpolypyrrolidone (PVPP). Polyphenolics bind to PVPP under acidic conditions and can then be removed by centrifuging (Van Alstyne 1995).

Feeding preference experiment. Ascophyllum nodosum plants from the induction experiment were used in a subsequent feeding preference experiment. The feeding experiment was run for $1 \mathrm{wk}$ in a controlled temperature room. Adult individuals $(>1 \mathrm{~cm})$ of the grazer ldotea granulosa were placed individually in plastic containers and starved for $1 \mathrm{~d}$ before the start of the experiment. Apical shoots of equal size $(\sim 5 \mathrm{~cm})$ were collected from the algae used in the preceding induction experiment. Two shoots of algae were simultaneously offered to each herbivore. One of the algal shoots was always from a fresh control plant and the other from one of the 4 treatments of the preceding induction experiment. The control shoot placed in each container was intended to serve as an alternative food in order to give the herbivore a true food choice and not forcing them to eat the shoots which had been experimentally treated. Data on weight changes of the control shoots were not included in the statistical analysis. An equal number of containers with algal shoots but without grazers was set up in order to control for autogenic changes in algal weight (Peterson \& Renaud 1989). The control data on autogenic changes were randomly paired with data on grazed algae and the difference was used as the variable measuring consumption by the grazer (Roa 1992). To compensate for small differences in the initial weight of the algal shoots percentage data on weight changes were used instead of absolute weights.

Statistical analysis. Datā on individual, relative (\%) changes in phloratannin concentrations and data on tissue-N and carbon content at the end of the induction experiment were analyzed by a mixed model ANOVA with Simulated grazing (2 levels) and UV-B radiation (2 levels) as fixed, orthogonal factors and Frame (2 levels) as a random factor nested within UV-B radiation. Consumption data from the feeding preference experiment were analyzed by a 2 way ANOVA with Simulated grazing and UV-B radiation as fixed, orthogonal factors. The relationships between tissue- $\mathrm{N}$ content and phlorotannin concentration were analyzed by linear regression. Prior to the statistical analyses, data were tested for homogeneity of variances with Cochran's test and transformed when required (Winer et al. 1991, Underwood 1997).

\section{RESULTS}

For data on phlorotannins, nitrogen content and $\mathrm{C}: \mathrm{N}$ ratios the nested factor Frame and the interaction term between Frame and Simulated grazing had pvalues $>0.3$ (not included in Tables $1 \& 2$ ) and a pooling procedure was applied where these terms were eliminated and their mean squares were pooled with the residual mean square (Winer 1991, Underwood 1997). 


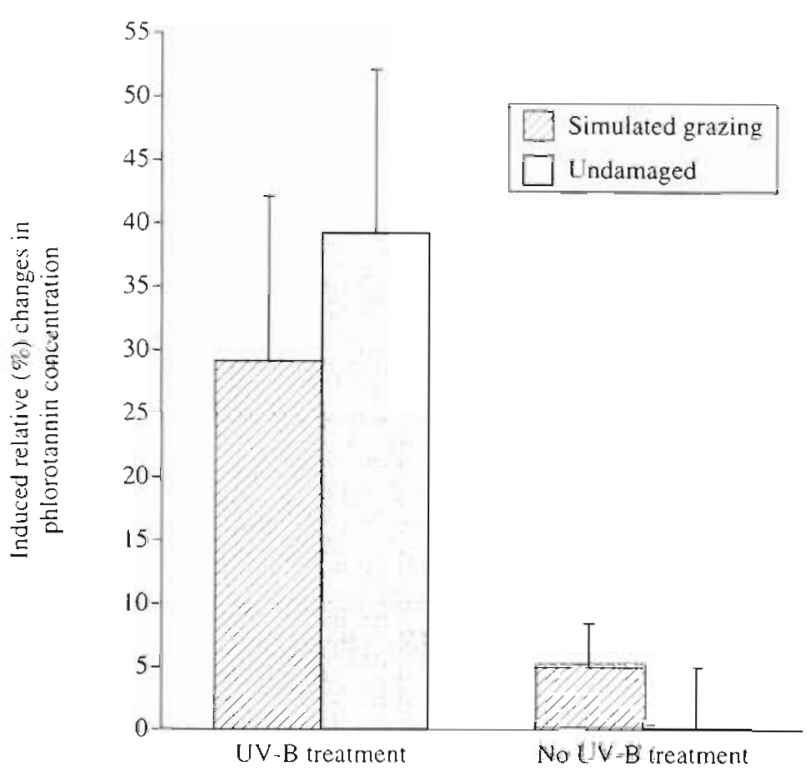

Fig. 1. Ascophyllum nodosum. Relative change (percentage of initial concentration) in phlorotannin levels following simulated grazing and increased UV-B radiation. Error bars are $+\mathrm{SE}(\mathrm{n}=12)$

Table 1. Ascophyllum nodosum. Analysis of variance of experimentally induced relative changes ( $\%$ of initial concentration) in phlorotannin concentration

\begin{tabular}{|lrrrc|}
\hline Factor & df & MS & $F$ & p \\
\hline Simulated grazing & 1 & 21.4 & 0.100 & $>0.75$ \\
UV-B radiation & 1 & 1700.5 & 7.822 & $<0.01$ \\
Simulated grazing $\times$ UV-B & 1 & 247.0 & 1.136 & $>0.25$ \\
Residual & 44 & 217.4 & & \\
\hline
\end{tabular}

The UV-B treatment induced a significant and substantial increase in mean phlorotannin concentration (Table 1, Fig. 1), from 4.8 to $6.2 \%$ of dry weight. In contrast, there was no significant change in phlorotannin levels following simulated grazing (Table 1, Fig. 1). Furthermore, there was no significant interaction between the 2 treatments, simulated grazing and UV$B$ radiation, indicating that the effect of UV-B irradi-

Table 2. Ascophyllum nodosum. Analysis of variance of nitrogen content $\left(\mathrm{mg} \mathrm{g}^{-1}\right.$ dry wt) and carbon:nitrogen ratio (log-transformed data) in tissue plants at the end of the induction experiment

\begin{tabular}{|c|c|c|c|c|c|c|c|c|}
\hline \multirow[t]{2}{*}{ Factor } & \multicolumn{4}{|c|}{ Tissue nitrogen } & \multicolumn{4}{|c|}{ C:N ratio } \\
\hline & $\mathrm{df}$ & $\mathrm{MS}$ & $F$ & $\mathrm{p}$ & $\mathrm{df}$ & MS & $F$ & $\mathrm{p}$ \\
\hline Simulated grazing & 1 & 0.002 & 0.55 & $>0.45$ & 1 & 6.8 & 0.50 & $>0.50$ \\
\hline UV-B radiation & 1 & 0.022 & 8.01 & $<0.01$ & 1 & 126.8 & 8.43 & $<0.01$ \\
\hline Simulated grazing $\times U V-B$ & 1 & 0.001 & 0.32 & $>0.55$ & 1 & 1.38 & 0.89 & $>0.75$ \\
\hline Residual & 44 & 0.003 & & & 44 & 15.0 & & \\
\hline
\end{tabular}
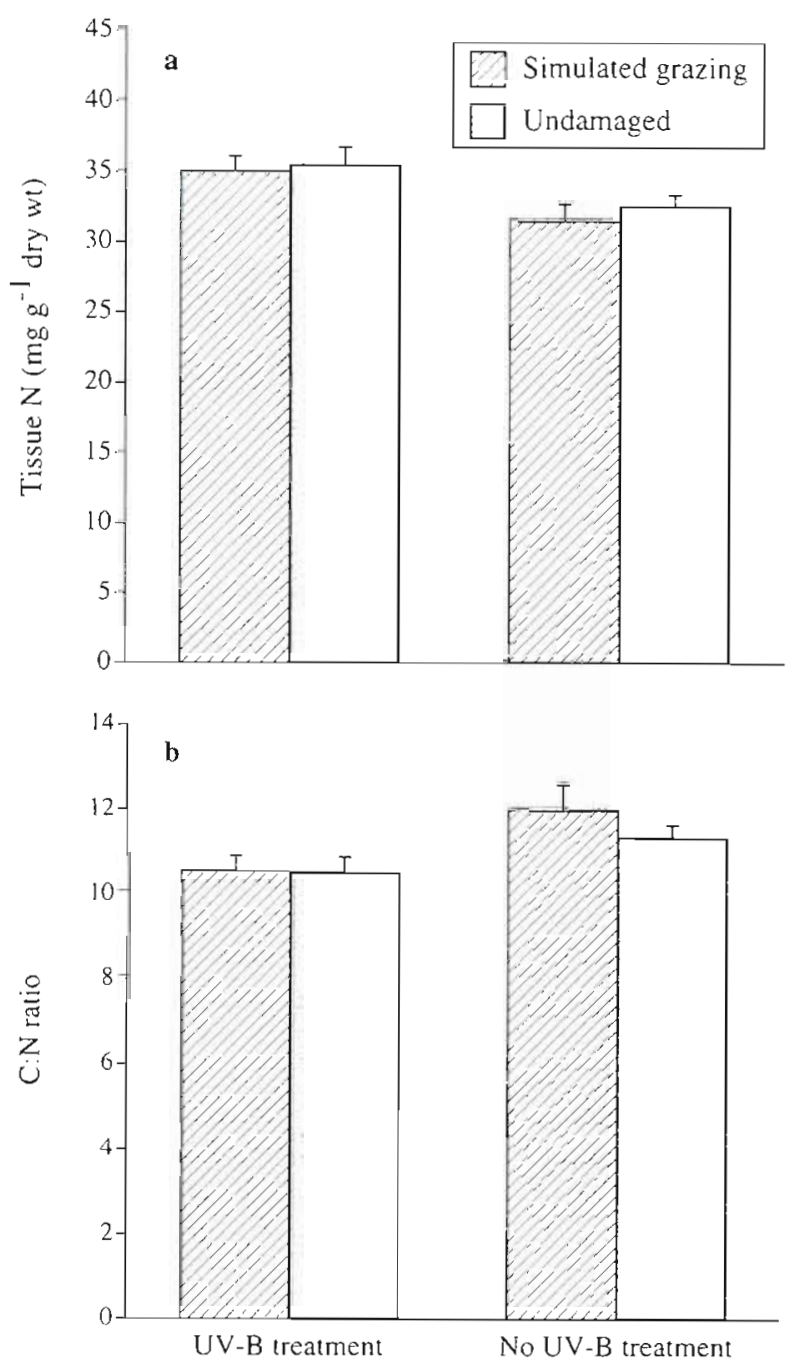

Fig. 2. Ascophyllum nodosum. (a) Tissue nitrogen content and (b) $C: N$ ratios following simulated grazing and increased $\mathrm{UV}-\mathrm{B}$ radiation. Error bars are $+\mathrm{SE}(\mathrm{n}=12)$

ance on phlorotannin production was independent of clipping damage.

Ascophyllum nodosum plants placed underneath the UV light frames had slightly but statistically significantly higher tissue- $N$ content than plants underneath the control frames (Table 2, Fig 2a); the reverse was true for $\mathrm{C}: \mathrm{N}$ ratios, with plants underneath the control frames showing significantly higher values than plants underneath the UV light frames (Table 2, Fig. 2b). There was no significant relationship between tissue$\mathrm{N}$ and phlorotannin concentrations for algae exposed to UV light treatment (linear regression, $\mathrm{R}^{2}=0.013, p>0.05$ ), nor for algae under control frames (linear regression, $R^{2}=0.068, p>0.05$ ) 


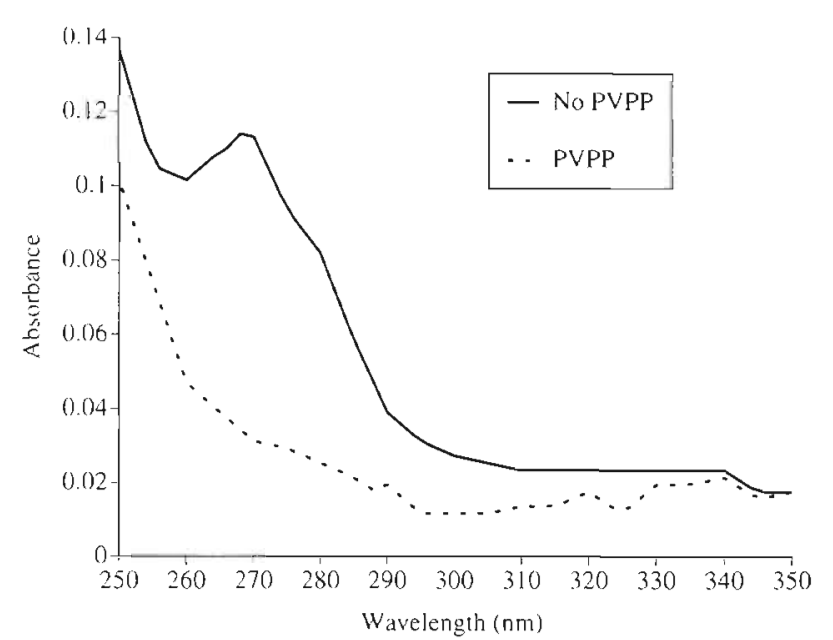

Fig. 3. Ascophyllum nodosum. Absorption spectra of extracts before and after removal of phlorotannins with polyvinylpolypyrrolidone (PVPP)

Table 3. Ascophyllum nodosum. Analysis of variance for the feeding preference experiment. The analysis was done on the amount of tissue (proportion of initial wet mass, arcsin-transformed data) consumed by the grazer Idotea granulosa. Algal tissues were collected from plants of the preceding 2 -factor (simulated grazing and UV-B radiation) induction experiment

\begin{tabular}{|lrrrc|}
\hline Factor & df & MS & $F$ & $\mathrm{p}$ \\
\hline Simulated grazing & 1 & 182.34 & 0.90 & $>0.35$ \\
UV-B radiation & 1 & 3873.3 & 18.92 & $<0.001$ \\
Simulated grazing $\times$ UV-B & 1 & 299.2 & 1.46 & $>0.20$ \\
Residual & 36 & 204.7 & & \\
\hline
\end{tabular}

Simulated grazing had no effect on tissue- $\mathrm{N}$ concentrations, or C:N ratios (Table 2, Fig. 2a, b)

The light absorption spectrum of the pooled Ascophyllum nodosum extract showed an absorption peak at $268 \mathrm{~nm}$ which disappeared after treatment with PVPP (Fig. 3). This is the same $\lambda_{\max }$ which has previously been reported for phlorotannin extracts of $A$. nodosum (Ragan \& Glombitza 1986). The spectra also revealed that extracted phlorotannins contribute to absorption of UV-B light (280 to $320 \mathrm{~nm}$ ) (Fig. 3).

Obvious differences in feeding by Idotea granulosa on Ascophyllum nodosum shoots exposed to the different experimental treatments in the induction experiment were observed (Table 3, Fig. 4). There was a significant $(\mathrm{p}<0.05)$ preference, in terms of algal biomass changes, of $I$. granulosa for algae that had been exposed to increased UV-B light. As for the results on algal tissue constituents in the preceding induction experiment, there was no apparent effect of the simulated grazing treatment on the susceptibility of the algae to the grazer I. granulosa (Fig. 4).

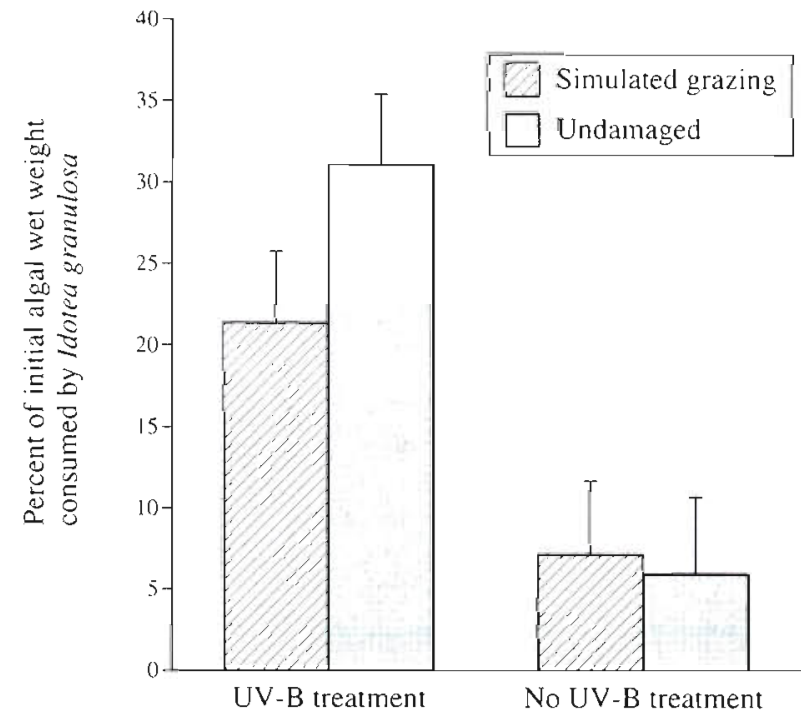

Fig. 4. Ascophyllum nodosum. Relative amount (percent of initial wet weight) of shoots consumed by Idotea granulosa in the feeding preference experiment. The $A$. nodosum shoots were collected from the preceding induction experiment, with 2 treatments, simulated grazing and increased UV-B radiation. Error bars are $+\mathrm{SE}(\mathrm{n}=10)$

\section{DISCUSSION}

This is the first study to demonstrate that UV radiation can be an important factor to explain intraspecific variation in phlorotannin content of marine brown algae. Individuals of Ascophyllum nodosum responded to a $\sim 50 \%$ addition of $\mathrm{UV}-\mathrm{B}$ radiation by a $-30 \%$ increase in mean phlorotannin concentration. An adaptive explanation to this induction is that tannins are produced to protect against photodestruction of plant tissue, principally caused by UV light. Compounds which can protect plant cells against harmful incident UV light should be produced in the outer celllayers to be most effective. This seems to be the case for phlorotannins in algae where cortical tissues generally contain higher concentrations than inner tissues (Ragan \& Glombitza 1986, Tugwell \& Branch 1989 , Lowell et al. 1991). Nevertheless, UV screening has so far not been regarded as a likely explanation for the production of tannins in algae (Steinberg 1992) since simple phenolic compounds such as phloroglucinolbased phlorotannins have absorption maxima at wavelengths (260 to $280 \mathrm{~nm}$ ) somewhat shorter than UV-B (280 to $320 \mathrm{~nm}$ ) (Ragan \& Craigie 1980, Steinberg 1992, Waterman \& Mole 1994). However, the absorption spectra of extracts from $A$. nodosum indicate that the phlorotannins can contribute to absorption also in the UV-B range, although the molar absorptivity of brown algal phlorotannins in vivo remains to be more rigorously examined in order to evaluate their poten- 
tial role as UV-B light screeners. To further evaluate the possible UV screening function of phlorotannins in A. nodosum, and other seaweeds, the effect of UV-B radiation on phlorotannin production should also be studied in other seasons, since natural irradiance level and the developmental stage of the algae are likely to influence the physiological responses of the algae, and under different environmental conditions, e.g. increased/decreased nutrient availability.

The most common explanations for the effect of increased irradiance on phlorotannin production are based on the carbon-nutrient balance model (Bryant et al. 1983). According to this model an increase in light, when nutrient availability is limited, will result in an excess of carbon which can be used for production of carbon-based chemical defense, e.g. polyphenolics. Correlative studies on the relationship between tissue nitrogen and phlorotannins (Ilvessalo \& Tuomi 1989. Yates \& Peckol 1993) and nutrient enrichment experiments in situ (Yates \& Peckol 1993, Peckol et al. 1996) and in the laboratory (Arnold et al. 1995) have shown that this model can be relevant to phlorotannin production in brown algae. The carbon-nutrient balance model is not directly applicable to the present study since the addition of PAR from the UV lamps was negligible. However, the increased production of phlorotannins might be an indirect effect caused by effects of $U V-B$ radiation on nutrient transformations in the algae. For microalgae it has been shown that both the uptake of ammonium and the metabolism of nitrogenous amino acids can be influenced by UV irradiation (Döhler et al. 1991, Döhler 1992). Furthermore, any increased production of UV-B protective components with high nitrogen content, e.g. proteins, could increase the nitrogen demand of the plant cells (Wängberg et al. 1995). This could in turn cause a nutrient deficit and an excess of carbon which could be used for polyphenolic production in accordance with the carbon-nutrient balance model. However, our results do not indicate that the UV-light-induced increase in Ascophyllum nodosum phlorotannin production was an indirect effect caused by a nutrient deficit. The UVlight-exposed algae actually had a slightly higher level of tissue- $\mathrm{N}$ than the control algae.

The predominant focus of research on phlorotannins has been on their function in algal-herbivore interactions. One crucial step in understanding the role and evolution of phlorotannins in herbivore defense is to find out if they function as inducible or constitutive defenses. So far, there seems to be weak support for the notion that induced defense models should be generally relevant for phlorotannins in marine algae (see Steinberg 1994, Peckol et al. 1996 for further discussion). This conclusion is further supported by the results of the present study where simulated herbivory caused no changes in phlorotannin concentrations. However, more studies covering different types of damages, including natural herbivory, as well as different seasons and experimental conditions and durations are needed before more reliable conclusions about the lack or existence, and relative importance, of herbivore-induced phlorotannin production in Ascophyllum nodosum can be drawn.

Despite the increased concentration of phlorotannins in UV-B treated algae, the isopod Idotea granulosa preferred to graze on shoots from these algae. This indicates that increased phlorotannin production does not deter I. granulosa from feeding on algal tissue, which supports the conception that small marine herbivores are in general relatively tolerant to chemical defenses of algae (Hay \& Fenical 1992, but see Poore 1994). We can only speculate about the reasons why $I$. granulosa preferred to feed on the UV-light-exposed algae, in spite of the increased phlorotannin level. The somewhat higher nitrogen content in the UV-treated algae might reflect a change in nutritional value, e.g. increased protein content, which could have attracted the grazers. The importance of intraspecific variation in nutritional value of brown algae has, to our knowledge, not been tested in any feeding preference experiments. An alternative explanation is that the additional UV radiation caused a change in the mechanical properties of the algae, i.e. decreased toughness. However, data published so far suggest that intraspecific variation in brown algal toughness is not an important factor to explain feeding preferences of marine herbivores (Lowell et al. 1991, Poore 1994).

So far, ecological research on induction of phlorotannin production, as well as other plant phenolics production, has mainly been occupied with 2 factors, herbivory and resource availability. Our results give support to the opinion that more effort should be devoted to also examine the importance of other factors, such as UV radiation, to explain intraspecific variation in phlorotannins. Such studies should preferably be designed to experimentally test for the relative importance and interactions among different factors, e.g. UV-B radiation, season and nutrient availability. This requires fully crossed factorial experiments where different treatments are applied simultaneously. Peckol et al. (1996) simultaneously examined the effect of simulated grazing and nitrogen enrichment on phlorotannins in Fucus vesiculosus L. in the western Atlantic. Although they did not statistically test for interactive effects between the 2 factors it was obvious from the presented data that the effect of clipping was sometimes dependent on nitrogen availability, and vice versa, and that the effect of both treatments varied in time and space. These results together with results from previous experiments with single or separate 
treatments (e.g. Van Alstyne 1988, Yates \& Peckol 1993, Steinberg 1994, Arnold et al. 1995) indicate that intraspecific variation in phlorotannins is determined by an interaction of environmental and defenserelated factors. More experimental data on the type and magnitude of such interactions would lead to a better understanding of the ecological role of phlorotannins. It would also, together with phylogenetic, genetic and biochemical data, provide an empirical basis for the formation and evaluation of evolutionary models to explain interspecific variation in algal polyphenolics (e.g. Coley et al. 1985).

Acknowledgements. S. A. Wängberg generously lent us UV light equipment. S.- $\AA$. Wängberg, S. Odmark and C. Nilsson gave useful advice on UV light experiments. We thank $M$. Lindegarth and P. Jonsson for stimulating discussions on experimental designs and Hans Olsson for help with analyses of tissue carbon and nitrogen. We are also grateful to all staff and students at Tjärnö Marine Biological Laboratory for their helpfulness and hospitality. Research support was provided by the Royal Swedish Academy of Science (Hierta-Retzius foundation) and the foundation of Helge Ax:son Johnson. The foundations of Knut and Alice Wallenberg, Wilhelm and Martina Lundgren and Kapten Carl Stenholm, and the Swedish Natural Science Research Council through contract B-BU 9949-302 provided additional support.

\section{LITERATURE CITED}

Aberg P (1990) Population ecology of Ascophyllum nodosum: demography and reproductive effort in stochastic environments. PhD thesis, Göteborg University

Ảberg P, Pavla H (1997) Temporal and multiple scale spatial variation in juvenile and adult abundance of the brown alga Ascophyllum nodosum. Mar Ecol Prog Ser (in press)

Arnold TM, Tanner CE, Hatch WI (1995) Phenotypic variation in polyphenolic content of the tropical brown alga Lobophora variegata as a function of nitrogen availability. Mar Ecol Prog Ser 123:177-183

Brawley SH, Fei XG (1987) Studies of mesoherbivores in aquaria and in an unbarricaded mariculture farm on the Chinese coast. J Phycol 23:614-623

Bryant JP, Chapin FS, Klein DR (1983) Carbon/nutrient balance of boreal plants in relation to vertebrate herbivory. Oikos 40:357-368

Coley PD, Bryant JP, Chapinand FS (1985) Resource availability and plant antiherbivore defense. Science 230 : 895-899

Döhler G (1992) Impact of UV-B radiation on uptake of $\cdots$ - vammonia and ${ }^{15} \mathrm{~N}$-nitrate by phytoplankton in the Wadden Sea. Mar Biol 112:485-489

Döhler G, Hagmeier GE, Krause KD (1991) Impact of solar UV radiation on the uptake of ${ }^{15} \mathrm{~N}$-ammonia and ${ }^{15} \mathrm{~N}$-nitrate by marine diatoms and natural phytoplankton. Biochem Physiol Pflanzen 187:293-303

D'Surney SJ, Tschaplinski TJ, Edwards NT, Shugart LR (1993) Brological responses of two soybean cultivars exposed to enhanced UVB radiation. Environ Exp Bot 33: $347-356$

Harvell CD (1990) The ecology and evolution of inducible defenses. Q Rev Biol 65:323-340

Hay ME, Fenical W (1992) Chemical mediation of seaweed- herbıvore interactions. In: John DM, Hawkıns SJ, Price JH (eds) Plant-ranimal interactions in the marine benthos. Systematics Sssociation Spec Vol 46, Clarendon Press, Oxford, p 319-337

Herms DA, Mattson WJ (1992) The dilemma of plants: to grow or defend. Q Rev Biol 67:283-335

Ilvessalo H. Tuomi J (1989) Nutrient availability and accumulation of phenolic compounds in the brown alga Fucus vesiculosus. Mar Biol 101:115-119

Karban R, Myers JH (1989) Induced plant responses to herbivory. Annu Rev Ecol Syst 20:331-348

Lowell RB, Markham JH, Mann K (1991) Herbivore-like damage induces increased strength and toughness in a seaweed. Proc R Soc Lond B 243:31-38

Pavia H, Áberg P (1996) Spatial variation in polyphenolic content of Ascophyllum nodosum (Fucales, Phaeophyta). Hydrobiologia 326/327:199-203

Peckol P, Krane JM, Yates JL (1996) Interactive effects of inducible defense and resource availability on phlorotannins in the North Atlantic brown alga Fucus vesiculosus. Mar Ecol Prog Ser 138:209-217

Peterson CH, Renaud PE (1989) Analysis of feeding preference experiments. Oecologia 80:82-86

Poore AGB (1994) Selective herbivory by amphipods inhabiting the brown alga Zonaria angustata. Mar Ecol Prog Ser 107:113-123

Ragan MA, Craigle JS (1980) Quantitative studies on brown algal phenols. IV. Ultraviolet spectrophotometry of extracted polyphenols and implications for measuring dissolved organic matter in sea water. J Exp Mar Biol Ecol 46: 231-239

Ragan MA, Glombitza KW (1986) Phlorotannins, brown algal polyphenols. In: Round FE, Chapman DJ (eds) Progress in phycological research, Vol 4. Biopress Ltd, Bristol, p $129-241$

Ragan MA, Jensen A (1977) Quantative studies on brown algal phenols. I. Estimation of absolute polyphenol content of Ascophyllum nodosum (L.) Le Jol. and Fucus vesiculosus (L.). J Exp Mar Biol Ecol 30:209-221

Roa R (1992) Design and analysis of multiple-choice feeding preference experiments. Oecologia 89:509-515

Salemaa H (1987) Herbivory and microhabitat preferences of Idotea spp. (Isopoda) in the Northern Baltic Sea. Ophelia 27:1-15

Steinberg PD (1985) Feeding preferences of Tegula funebralis and chemical defenses of marine brown algae. Ecol Monogr 55:333-349

Steinberg PD (1989) Biogeographical variation in. brown algal polyphenolics and other secondary metabolites: comparison between temperate Australasia and North America. Oecologia 78:373-382

Steinberg PD (1992) Geographical variation in the interaction between marine herbivores and brown algal secondary metabolites. In: Paul VJ (ed) Ecological roles of marine natural products. Cornell University, New York, p 51-92

Steinberg PD (1994) Lack of short-term induction of phlorotannins in the Australasian brown algae Ecklonia radiata and Sargassum vestitum. Mar Ecol Prog Ser 112: $129-133$

Tugwell S, Branch GM (1989) Differential polyphenolic distribution among tissues in the kelps Ecklonia maxima, Laminaria pallida and Macrocystis augustifolia in relation to plant-defense theory. J Exp Mar Biol Ecol 129:219-230

Underwood AJ (1997) Experiments in ecology: their logical design and interpretation using analysis of variance. Cambridge University Press, Cambridge

Van Alstyne KL (1988) Herbivore grazing increases polyphe- 
nolic defenses in the intertidal brown alga Fucus distichus. Ecology 69:655-663

Van Alstyne KL (1995) Comparison of three methods for quantifying brown algal polyphenolic compounds. J Chem Ecol 21:45-58

Wängberg $\mathrm{S} \AA$, Selmer JS, Ekelund NGA, Gustavsson K (1995) Effects of increased UV-B radiation on the Nordic marine ecosystem - a literature review. The Nordic Coun-

Editorial responsibility: Anthony Underwood (Contributing Editor), Sydney, New South Wales, Australia cil of Ministers, Göteborg

Waterman PG, Mole S (1994) Analysis of phenolic plant metabolites. Blackwell Scientific Publications, Oxford

Winer BJ, Brown DR, Michels KM (1991) Statistical principles in experimental design. McGraw-Hill, New York

Yates JL, Peckol P (1993) Effects of nutrient availability and herbivory on polyphenolics in the seaweed Fucus vesiculosus. Ecology 74:1757-1766

Submitted: February 12, 1997; Accepted: July 22, 1997 Proofs received from author(s): August 27, 1997 